\title{
Non-Viral Causes of Hepatocellular Carcinoma
}

\author{
David H. Van Thiel • Guiliano Ramadori
}

Published online: 7 September 2010

(C) The Author(s) 2010. This article is published with open access at Springerlink.com

\begin{abstract}
Introduction Hepatocellular carcinoma (HCC) is a major cause of cancer worldwide. The vast majority of cases occur in individuals with a chronic HBV or HCV infection. In addition, a number of metabolic diseases of the liver are associated with the development of HCC.

Pathophysiologic Mechanisms The mechanisms responsible for the progression of the metabolic liver disease and HCC differ from those associated with viral liver disease. Conclusions The purpose of this report is to describe the mechanisms responsible for the disease progression and $\mathrm{HCC}$ in case of metabolic liver disease. A secondary goal is to identify the frequency of $\mathrm{HCC}$ development in the disorders described.
\end{abstract}

Keywords Hepatocellular carcinoma $\cdot$ Cancer $\cdot$ NAFLD . NASH

\section{Introduction}

Hepatocellular carcinoma [1-6] is a major cause of cancer and cancer-related deaths worldwide. The vast majority of cases are a consequence of a preexisting chronic viral infection due to either hepatitis B with or without associated hepatitis D or hepatitis C [7-9].

D. H. Van Thiel $(\bowtie) \cdot G$. Ramadori

Rush University Medical Center,

Suite 158, POB, 1725 W. Harrison,

Chicago, IL 60612, USA

e-mail: david_vanthiel@rush.edu

D. H. Van Thiel · G. Ramadori

Zentrum Innere Medezin, August Georg University,

Gottingen, Germany
The number of cases directly related to hepatitis B (HBV) infection has remained stable worldwide with most of the cases of HBV-associated HCC occurring in Southeast Asia and Sub-Saharan Africa [7-9].

In contrast, the number of cases of HCV has increased and is expected to steadily increase over the next 20 30 years as a result of the continuing problem of $\mathrm{HCV}$ infection and disease chronicity [4, 10-13].

The majority of cases of HCV-related HCC occur in Europe and the Americas. The number of HCC cases that occur, independent of a preexisting viral infection, is increasing worldwide as a consequence of the global increase in individuals manifesting one or more of the components of the metabolic syndrome that include obesity, coronary artery disease, hyperlipidemia, type 2 diabetes mellitus, gout, sleep apnea, and nonalcoholic fatty liver diseases (NAFLD) or nonalcoholic steatohepatitis (NASH) [14-23].

In addition, a much smaller yet substantial number of cases are a consequence of chronic alcohol-associated cirrhosis or one or a large number of inherited metabolic liver diseases, the most common of which are alpha-1 antitrysin deficiency, hemochromatosis, Wilson's disease, and type 1 tyrosenemia [24].

Finally, the few residual cases of non-viral HCC that have been ascribed to environmental exposures to include aflatoxin in contaminated grains, tobacco use, oral contraceptives, and use of anabolic steroids.

\section{Pathophysiologic Mechanisms}

The underlying mechanisms responsible for these non-viralassociated HCC are in general a consequence of an epigenetic event that persists and disrupts the normal cell cycle that 
contract cellular proliferation, differentiation, and senescence or a genetic polymorphism that enhances the risk for HCC development [24].

Considerable data exist for the former epigenetic factor hypothesis while relatively little and variable data exist for the presence of an intrinsic genetic mutation leading to the development of HCC other than those associated with wellrecognized metabolic liver diseases.

Regardless of the specific epigenetic mechanisms involved, enhanced oncogene transcription or its promotion, reduced degradation of a cyclin, DNA, RNA on regulatory protein occurring as a result of hyper- or hypo-methylation of DNA and/or RNA, free radical induced per oxidation or the presence of either reactive oxygen or nitrosyl compounds, occurring as a result of oxidative stress.

The vast majority of non-viral-associated HCC manifest biochemical evidence of insulin resistance and/or deregulation of a growth factor (including insulin) [25, 26].

As a direct consequence of these various mechanisms leading to the development in HCC, it is not surprising that HCCs are heterogeneous in their growth rates, degree of cellular differentiation (morphology), cellular origin, and potential for metastasis.

\section{Representative Disease Examples}

\section{Alcoholic Liver Disease}

It is estimated that $15-20 \%$ of alcoholics with cirrhosis develop $\mathrm{HCC}$ at a rate of 3-4\%/year. In rare cases, occurring in the absence of cirrhosis either an unrecognized low-grade chronic hepatitis $\mathrm{C}$ or an occult case of HBV infection can be identified and manifested by $\mathrm{H}$ B core antibody positivity.

The principal pathophysiologic mechanism leading to HCC in chronic alcoholics, however, is an oxidative stress induced within the liver as a direct consequence of the metabolism of ethanol, its first metabolic product acetaldehyde, and possibly acetate by mitochondria and the rich endoplasmic recticulum found in the hepatic cytosil $[27,28]$.

The resultant loss of ATP production and cellular injury occurring as a result of membrane phospholipid and protein oxidation, protein carbonyl formation, and the production of 1-hydroxyethanol radicals as well as other alkyl free radicals leads to altered cell signaling mechanisms, transcription, and translation errors that ultimately result in the development of HCC.

The consequences of ethanol related nutritional perturbations that include folate deficiency, pyridoxylphosphate deficiency, and a diet rich in carbohydrates and lipids at the expense of protein are additional factors that contribute to the enhanced expression of protocongenes and oncogenes and the risk of HCC development [29-35].

\section{NAFLD and NASH}

The current worldwide epidemic of NAFLD occurring in children as well as adults and in lean as well as obese individuals has resulted in a remarkable increase in the number of cases of HCC occurring in the Western World and more opulent numbers of the Third World who have no evidence for either current or past $\mathrm{HBV}$ and/or $\mathrm{HCV}$ infection [16-20].

Currently, NAFLD is considered a benign condition that can progress to NASH in approximately $20 \%$ of cases. In turn, $20 \%$ of NASH cases are thought to progress to cirrhosis. HCC can develop in individuals with NASH combined with cirrhosis and also albeit less often in cases with NASH occurring in the absence of cirrhosis. The actual rate of HCC development in NASH-associated cirrhosis is estimated to be similar to that occurring in alcoholics with cirrhosis (3-4\%/year). There are no current estimates of the rate of HCC development in cases of NASH without cirrhosis but increasingly, such cases are being recognized.

The pathophysiologic mechanisms leading to $\mathrm{HCC}$ in NASH and NASH plus cirrhosis appear to mirror the events occurring in alcoholic liver disease enhanced further by the presence of insulin resistance.

Insulin resistance is known to be associated with a reduction of tyrosine, phosphorytation in many different cells and organs. As a result, alternate cellular pathways affecting cell proliferation and differentiation are upregulated. The combination of the upregulation of proteins responsible for cellular proliferation and differentiation coupled with the net oxidation stress induced by the hepatic metabolism of triglycerides is a potent driving force for the development of HCC.

\section{Hepatic Disorders of Iron and Copper Metabolism}

Cases of both HFE and non-HFE associated determined hepatic iron overload (hemochromatosis) as well as cases of excessive hepatic copper retention as occurs in Wilson's disease result in the development of cirrhosis, and in 7.5$30 \%$ of these cirrhotic cases, a HCC develops. Rare cases of non-cirrhotic HCC have been reported in both forms of hepatic metal overload [36-42].

The pathophysiology of these disorders is characterized by mitochondrial dysfunction with the production of reactive oxygen and reactive nitrozyl species that characterize oxidative stress. The resultant disruption of cell cycling in these two disorders is characterized by enhanced cellular replication as well as an increased apoptosis rate. 
Insulin resistance associated with cirrhosis is common in individuals with either hepatic iron or copper overload and may further enhance the risk of HCC occurring as a consequence of the more obvious oxidation stress present in these two disorders. Iron reduction therapy reduces the prevalence of cirrhosis and, as a result, HCC in cases of hemochromatosis. Most cases of Wilson's disease are recognized clinically only after cirrhosis has developed, but it is likely that copper reduction therapy in precirrhotic individuals with Wilson's disease identified by means of family screening may lead to a reduced rate of $\mathrm{HCC}$ development as well.

\section{Alpha-1 Antitrypsin Deficiency}

Alpha-1 antitrypsin deficiency is an autosomal recessive disorder resulting in the expression of a defective alpha-1 antitrypsin protein as a consequence of the presence of an abnormal allele. The abnormal alleles currently recognized in cases of alpha antitrypsin deficiency include, $\mathrm{Z}$, $\mathrm{S}, \mathrm{F}$, and null alleles. Individuals who are homozygous for an abnormal allele or are a compound heterozysate having two different abnormal alleles manifest the clinical disorder.

HCC is common in children with alpha-1 antitrypsin deficiency and cirrhosis as well as in adults who are 5060 years of age. In the adult cases of alpha-1 antitrypsin with cirrhosis, HCC is reported to occur in $31-67 \%$ of cases [43-45].

The hepatic endoplasmic reticulum and mitochondrion in individuals with alpha-1 antitrypsin deficiency demonstrate morphologic and biochemical abnormalities. As a result, the sum of the many different cellular injuries associated with oxidative stress associated with mitochondrial injury is thought to be the driving force for $\mathrm{HCC}$ development in cases of alpha-1 antitrypsin deficiency.

\section{Tyrosinemia Type 1 or Hepatorenal Tyrosenemia}

Tyrosenemia type 1 is an autosomal recessive disorder due to deficiency of Fummaryl acetoacetate hydrolase which results in an accumulation of Fummaryl acetonatate and malyl aceto acetate [46].

Type 1 tyrosinemia has a worldwide prevalence of $1 /$ 100,000 live births but occurs at an increased rate as high as $1 / 2,000$ live births in specific geographic locations [47]. Apoptosis characterizes the histological appearance of the liver affected by type 1 tyrosinemia [48]. The apoptosis signal appears to be fumaryl acetoacetate. Both fumarylacetoacetate and malyl acetoacetate are alkylating agents that induce DNA and RNA mutagenesis. As is the case in all of all of the preceding diseases, a prominent oxidative stress occurs in tyrosinemia as a consequence of the metabolism of malylacetone, fummarylacetone, succinylacetate, and succinylacetone.

\section{Summary and Conclusions}

The epigenetic and resultant genetic alterations produced as a consequence of an excessive oxidative stress characterizes the diseases of metabolism that are associated with the development cirrhosis and ultimately HCC.

These metabolic alterations result in gene over- and underexpression enhanced proliferation, reduced apoptosis, proto-oncogene, oncogene over expression, and reduced levels of cycling dependent kinase inhibitors.

The specific alteration that is most evident in a given disease associated with HCC development varies with and across diseases making a more specific description of the pathogenesis of $\mathrm{HCC}$ any difficult.

Open Access This article is distributed under the terms of the Creative Commons Attribution Noncommercial License which permits any noncommercial use, distribution, and reproduction in any medium, provided the original author(s) and source are credited.

\section{References}

1. Ferlay J, Parkin DM, Pisani P, GLOBOCAN 2002. Cancer incidence, mortality and prevalence worldwide. Version 1.0. IARC Cancer Base No. 5. Lyon: IARC; 2004.

2. Bosch FX, Ribes J, Diaz M, Cleries R. Primary liver cancer: worldwide incidence and trends. Gastroenterology. 2004;127(5 Suppl 1):S5-S16.

3. El-Serag HB, Mason AC. Rising incidence of hepatocellular carcinoma in the United States. N Engl J Med. 1999;340:745-50.

4. El-Serag HB, Davila JA, Petersen NJ, McGlynn KA. The continuing increase in the incidence of hepatocellular carcinoma in the United States: an update. Ann Intern Med. 2003;139 (10):817-23.

5. Khan SA, Taylor-Robinson SD, Toledano MB, Beck A, Elliott $P$, Thomas HC. Changing international trends in mortality rates for liver, biliary and pancreatic tumours. J Hepatol. 2002;37:806-13.

6. Levi F, Lucchini F, Negri E, Boyle P, La Vecchia C. Cancer mortality in Europe, 1995-1999, and an overview of trends since 1960. Int J Cancer. 2004;110(2):155-69.

7. Di Bisceglie AM. Hepatitis C and hepatocellular carcinoma. Sem Liver Dis. 1995;1995:1564-9.

8. Lee WM. Hepatitis B virus infection. N Engl J Med. 1997;337: 1733-45.

9. Bosch FX, Ribes J, Cleries R, Diaz M. Epidemiology of hepatocellular carcinoma. Clin Liver Dis. 2005;9:191-211.

10. Tanaka Y, Hanada K, Mizokami M, Yeo AE, Shih JW, Gojobori T, et al. Inaugural article: a comparison of the molecular clock of hepatitis $\mathrm{C}$ virus in the United States and Japan predicts that hepatocellular carcinoma incidence in the United States will increase over the next two decades. Proc Natl Acad Sci USA. 2002;99:15584-9.

11. Tsukuma H, Hiyama T, Tanaka S, Nakao M, Yabuuchi $T$, Kitamura $\mathrm{T}$, et al. Risk factors for hepatocellular carcinoma 
among patients with chronic liver disease. $\mathrm{N}$ Engl J Med. 1993;328:1797-801.

12. Yoshizawa $\mathrm{H}$. Hepatocellular carcinoma associated with hepatitis $\mathrm{C}$ virus infection in Japan: projection to other countries in the forseeable future. Oncology. 2002;62 Suppl 1:8-17.

13. Liang TJ, Jeffers LJ, Reddy KR, DeMedina M, Parker IT, Cheinquer $\mathrm{H}$, et al. Viral pathogenesis of hepatocellular carcinoma in the United States. Hepatology. 1993;18:1326-33.

14. Bugianesi E, Leone N, Vanni E, Marchesini G, Brunello F, Carucci $\mathrm{P}$, et al. Expanding the natural history of nonalcoholic steatohepatitis: from cryptogenic cirrhosis to hepatocellular carcinoma. Gastroenterology. 2002;123:134-40.

15. Shimada M, Hashimoto E, Taniai M, Hasegawa K, Okuda H, Hayashi N, et al. Hepatocellular carcinoma in patients with nonalchoholic steatohepatitis. J Hepatol. 2002;37:154-60.

16. Yu AS, Keeffe EB. Nonalcoholic atty liver disease. Rev GE disord. 2002;2:11-9.

17. Metha K, Van Thiel DH, Shah N, Mobarhan S. Nonalcoholic fatty liver disease; pathogenesis and the role of antioxidants. Nutr Rev. 2002;60:289-93.

18. Baldridge AD, Peres-Atayde AR, Graeme-Cook F, Higgins L, Lavi JE. Idiopathic steatohepatitis in childhood: a multicenter retrospective study. J Pediatr. 1995;127:700-4.

19. Manton ND, Lipsett J, Moore DM, Davidson GP, Buourne AJ, Couper RTL. Non-alcoholic steatohepatitis in children and adolescents. Med J Aust. 2000;173:476-9.

20. Sorensen HT, Mellemkjaer L, Jepsen P, Thulstrup AM, Baron J, Olsen JH, et al. Risk of cancer in patients hospitalized with fatty liver: a Danish cohort study. J Clin Gastroenterol. 2003;36(4):356-9.

21. George K, Alberti MM, Zimmet P, Shaw J. The metabolic syndrome - a new worldwide definition. Lancet. 2005;366:1059-62.

22. El-Serag HB, Richardson PA, Everhart JE. The role of diabetes in hepatocellular carcinoma: a case-control study among USA Veterans. Amer J GE. 2001;96:2462-7.

23. Angulo P. Non-alcoholic fatty liver disease. New Engl J Med. 2002;346:1221-31

24. Van Thiel DH, Ramadori G. Metabolic disease and hepatocellular carcinoma. In: Carr B, editor. Hepatocellular carcinoma diagnosis and treatment, vol. 2. New York: Humana; 2010. p. 283-308.

25. Tal-Kremer S, Day CP, Reeves HL. Genetic basis of hepatocellular cancer. In: Ali S, Friedman SL, Mann DA, editors. Liver diseases biochemical mechanisms and new therapeutic insights. Enfield: Science; 2006. p. 273-308.

26. Tovar V, Alsinet C, Villanueva A, Hoshida Y, Chiang DY, Solé M, et al. IGF activation in a molecular subclass of hepatocellular carcinoma and pre-clinical efficacy of IGF-1R blockage. J Hepatol. 2010;52(4):550-9.

27. Arteel GE. Oxidants and antioxidants in alcohol-induced liver disease. Gastroenterology. 2003;124:778-90.

28. Baily SM, Cunningham C. Contribution of mitochondira to oxidative stress associated with alcoholic liver disease. Free Radic Biol Med. 2002;32:11-6.

29. Gloria L, Cravo M, Camilo ME, Resende M, Cardoso JN, Oliveria AG, et al. Nutritional deficiencies in chronic alcoholics: relation to dietary intake and alcohol consumption. Am J Gastroenterol. 1997;92:485-9.
30. Stickel F, Schuppan D, Hahn EG, Seitz HK. Cocarcinogenic effects of alcohol in hepatocarcinogenesis. Gut. 2002;51:132-9.

31. Fonda ML, Brown SG, Pendleton MW. Concentration of vitamin B6 and activity of enzymes of B6 metabolism in the blood of alcoholic and nonalcoholic men. Alc Clin Exper Res. 1989;3:804-9.

32. Simile MM, Pascale R, De Miglio MR, Nufris A, Daino L, Seddaiu MA, et al. Correlation between S-adenosyl-L-methionine content and production of c-myc, c-Ha-ras, and c-Ki-ras mRNA transcripts in the early statges of rat liver carcinogenesis. Cancer Lett. 1994;79:9-16.

33. Zapisek WF, Cronin GM, Lyn-Cook BD, Poirier LA. The onset of oncogene hypomethylation in the livers of rats fed methyl-deficient amino acid-defined diets. Carcinogenesis. 1992;13:1869-72.

34. Kass S, Pruss D, Wolffe AP. How does DNA methylation repress transcription? Trends Genet. 1997;12:444-9.

35. Kondo Y, Kanai Y, Sakamoto M, Mizokami M, Ueda R, Hirohashi S. Genetic instability and aberrant DNA methylation in chronic hepatitis and cirrhosis-A comprehensive study of loss of heterozygosity and microsatellite instability at 39 loci and DNA hypermethylation on $\mathrm{CpG}$ islands in microdissected specimens from patients with HCC. Hepatology. 2000;32:970-9.

36. Niederau C, Fischer R, Sonnenberg A, Stremmel W, Trampisch HJ, Strohmeyer G. Survival and causes of death in cirrhotic and in noncirrhotic patients with primary hemochromatosis. N Engl J Med. 1985;313(20):1256-62.

37. Adams PC. Hepatocellular carcinoma in hereditary hemochromatosis. Can J C Gastroenterology. 1993;7:37-41.

38. Niederau C, Fischer R, Pürschel A, Stremmel W, Häussinger D, Strohmeyer G. Long-term survival in patients with hereditary hemochromatosis. Gastroenterology. 1996;110(4):1107-19.

39. Fargion S, Fracanzani AL, Piperno A, Braga M, D’Alba R, Ronchi G, et al. Prognostic factors for hepatocellular carcinoma in genetic hemochromatosis. Hepatology. 1994;20(6):1426-31.

40. Cheng WS, Govindarajan S, Redeker AG. Hepatocellular carcinoma in a case of Wilson's disease. Liver. 1992;12:42-5.

41. Guan R, Oon CJ, Wong PK, Foong WC, Wee A. Primary hepatocellular carcinoma associated with Wilson's disease in a young woman. Postgrad Med J. 1985;61(714):357-9.

42. Polio J, Enriquez RE, Chow A, Wood WM, Atterbury CE. Hepatocellular carcinoma in Wilson's disease. Case report and review of the literature. J Clin Gastroenterol. 1989;11:220-4.

43. Eriksson S, Carlson J, Velez R. Risk of cirrhosis and primary liver cancer in alpha 1-antitrypsin deficiency. N Engl J Med. 1986;314 (12):736-9.

44. Erikson S. Cirrhosis and malignant hepatoma in alpha 1antitrypsin deficiency. Atca Med Scand. 1974;195:451-8.

45. Bull LN, Carlton VE, Stricker NL, Baharloo S, DeYoung JA, Freimer $\mathrm{NB}$, et al. Genetic and morphological findings in progressive familial intrahepatic cholestasis (Byler disease [PFIC-1] and Byler syndrome): evidence for heterogeneity. Hepatology. 1997;26(1):155-64.

46. Lindblad B, Lindstedt S, Steen G. On the enzymic defects in hereditary tyrosinemia. Proc Natl Acad Sci USA. 1977;74:4641-5.

47. Paradis K. Tyrosinemia: the Quebec experience. Clin Invest Med. 1996;195:311-6.

48. Endo F, Sun MS. Tyrosinemia type 1 and apoptosis of hepatocytes and renal tubular cells. J Inherit Metab Dis. 2002;25:227-34. 